\title{
Assessing Peruvian University Students' Preferences for Labor Conditions in Mining Site
}

\author{
Shuto Mikami ${ }^{1}$, Yutaka Ito ${ }^{2, *}$ and Hernan Gabriel Oyola Gonzales ${ }^{1}$ \\ 1 Department of Earth Resource Engineering and Environmental Science, Akita University, \\ 1-1 Tegatagakuen-machi, Akita City 010-8502, Akita Prefecture, Japan; mikami.kodomo@gmail.com (S.M.); \\ hoyolag@uni.pe (H.G.O.G.) \\ 2 Faculty of Regional Policy, The University of Shimane, 2433-2 Nobara-cho, Hamada, Shimane 697-0016, Japan \\ * Correspondence: yut-ito@u-shimane.ac.jp
}

Citation: Mikami, S.; Ito, Y.; Oyola Gonzales, H.G. Assessing Peruvian University Students' Preferences for Labor Conditions in Mining Site. Sustainability 2021, 13, 9648. https:// doi.org/10.3390/su13179648

Academic Editors: Andreas Ciroth, Claudia Di Noi and

Jesus Martinez-Frias

Received: 4 July 2021

Accepted: 25 August 2021

Published: 27 August 2021

Publisher's Note: MDPI stays neutral with regard to jurisdictional claims in published maps and institutional affiliations.

Copyright: (c) 2021 by the authors. Licensee MDPI, Basel, Switzerland. This article is an open access article distributed under the terms and conditions of the Creative Commons Attribution (CC BY) license (https:// creativecommons.org/licenses/by/ $4.0 /)$.

\begin{abstract}
The mining industry is one of the biggest industries and has a strong impact in Peru. Despite the mining industry's importance, it faces labor shortages and environmental risks. For these situations, mining students are important sources of workers not only as labor forces but also as skilled workers who can contribute to solving the environmental issues of mining companies. Thus, the purpose of this paper is to assess Peruvian university mining students' preferences for labor conditions in mining sites using a discrete choice experiment in order to promote efficient improvements in labor conditions in mining sites that contribute to stable employment and address environmental concerns. The number of respondents was 222 in two Peruvian universities, including males and females aged 16-35 years. The analysis's findings indicate that labor conditions at mining sites can be optimized by adjusting them to specific individual characteristics of potential mining workers, resulting in a more efficient working environment for companies and workers.
\end{abstract}

Keywords: mining labor; labor condition; working condition; conjoint analysis

\section{Introduction}

The mining industry is one of the biggest industries and has a strong impact in Peru. By the early 2010s, the value of Peru's mining exports averaged USD 25 billion, or 14\% of the gross domestic product and more than $50 \%$ of the total exports [1]. Research shows that in a part of Peru, namely, the Madre de Dios region, high-resolution satellite imaging data indicate that the geographic expanse of mining sites increased by 400\% from 1990 to 2012 because of the soaring price of gold following the world financial crisis [2]. In addition, the Peruvian mining industry has taken a major role as a supplier in the international market. According to an industrial report, Peru is the second-largest producer of copper, zinc, and silver, the third-largest producer of lead, and the sixth-largest producer of gold as of 2020 [3].

By contrast, local residents living near mine sites are occasionally perturbed by mining activities. The environmental impacts of mining activities lead to conflicts between local residents and mining companies [4]. For instance, gold-mining activities thriving in Peruvian rain forests lead to mercury exposures, and high concentrations of mercury among local residents pose health risks, especially for pregnant women and infants [5]. Moreover, water is also a bone of contention between local residents and mining companies. Mining activity requires water for separation, processing, and labor forces. Extraction and its impact on groundwater directly affect the ecosystem and compete with other consumers of water [6]. According to a report by Defensoría del Pueblo 2019, there were 714 active social-environmental conflicts related to mining activities in Peru in 2019 [7].

Green innovation by the mining company is a breakthrough in addressing those issues. Green innovations are organizations' novel business activities that reduce environmental risks or pollution and other negative impacts of the use of resources [8]. The workforce's 
skills and abilities are critical components of a firm's capability for green innovation. Furthermore, employees' academic background was a common factor in firms' decisions to promote green innovation [9]. Thus, companies are encouraged to employ people with academic backgrounds to address the environmental issues that lead to conflict between local residents and mining companies.

Although the mining industry requires skilled labor, the shortage of mining workers is a concern in Peru. According to an industrial report, it is presumed that for a decade from $2018,17,000$ workers will retire, and 36,000 workers will be needed for 804 new mining projects in Peru. The report also indicates that mining companies will need to consider incentives for new mining workers to work in the companies [10].

Hence, this study aimed to contribute to understanding the situation in Peru by identifying the factors affecting the decisions of mining students, who are potential employees of the mining industry, for labor conditions using a discrete choice experiment. This study also examined the trend between students' preferences and their sociodemographic background. Finally, marginal willingness to accept (MWTA) for each attribute of labor conditions can be estimated from the results of conjoint analysis. The MWTA result shows that the level of monetary values of each attribute could indicate potential compensations of each level of the attributes.

Job selection differs by income, job location, and other sociodemographic factors (e.g., family size, sex, and age). A discrete choice experiment was conducted in Australia among university students to understand their preferences for working conditions at a mining site and thus contribute to effective employment [11]. The survey included 93 university students majoring in studies related to mining. The study results indicate that students are concerned about wage, fatality rate, working position, commuting style, and the company operating the mining site. In addition, sociodemographic characteristics, namely, sex and students' university, were examined. Another study exists on the job preferences of a new mining labor force to attract potential workers to a remote working location in Australia [12]. The online study utilized a discrete choice experiment with randomly selected respondents from Brisbane. The respondents faced two different selection task scenarios: commuting and relocation. The factors for commuting were employment (length of contract and promotion opportunities), block shifts and days off, distance from Brisbane, and commuter bonus. Employment, housing type, town service, family package (education and housing subsidies), and relocation bonus were all considered in the relocation scenario. The study's findings indicate that the most important factor influencing relocation was the salary size. However, this study demonstrated that additional factors influence relocation decision making. A medium-term contract was preferred for commuting, while a long-term contract was preferred for relocation. Other studies in the following section have examined student preferences in job selection for other industries, assuming that university students are the industry's most valuable potential labor force. Workers in specific industries, such as mining, require specialized skills. Companies in this industry must employ an adequate number of skilled workers to ensure the mining site's sustainability. Thus, a better understanding of the factors influencing university students' decision to specialize in mining is critical for mining company management.

\subsection{Previous Studies on Labor Conditions in Mining Site}

In the mining industry, labor and ambient conditions are strongly related to psychological burdens such as strain and stress, which lead to health problems and low productivity. A study on psychological and physical hazards and their implications for employees' safety in the Ghanaian mining industry insisted that injuries, accidents, and near misses are associated with mining conditions. Accidents in a mining site were associated with ambient conditions such as excessive noise, heat stress, dusty conditions, and poor visibility. This study reported that high job demand and low control over workload are associated with low safety [13]. Another study focusing on workers' stress associated with productivity in the Australian mining industry claimed that employees residing in the mining town 
showed higher production costs than those commuting by fly-in/fly-out or drive-in/driveout. Moreover, employees on permanent day shifts showed higher productivity costs than those on a rotating shift. It also showed that higher stress leads to higher production costs and the female employees were more likely to want assistance for stress management than male employees, although female and male employees showed a similar average of impairment cost [14]. Another study examined the psychological strain in 71 miners working in 794 shifts across five mining plants in Hungary. The study focused on factors such as the presence of managers and temperature and illumination in the mining site that might affect their heart rate, indicating miners' strain. The study indicated that these factors also lead to strain in miners, for example, high temperature in mining sites leads to more strain, while brighter illumination leads to less strain [15]. Regarding the work environment related to the employees' well-being, a study by Donatella Di Marco estimated that employees' well-being is negatively impacted by a discriminatory environment [16]. Given that none of these factors apply to students without any work experience in the mining industry, the aforementioned labor conditions were not applied to this study.

\subsection{Previous Studies on Job Preferences in Various Industries}

Job preferences have been studied in various regions and industrial sectors using data from students majoring in specific academic fields, including accounting students in Malaysia [17], agricultural students in Germany [18], and nursing students in Kenya, South Africa, Thailand, and the UK [19,20]. Omar (2015) examined accounting students preferences for job conditions and found that the working environment was the most important factor in addition to the starting salary and employer reputation. Blaauw (2010) studied nursing students' preferences on working conditions in Kenya, South Africa, and Thailand and found that receptiveness to various human resource strategies differs between countries. The findings indicate that job preferences among nursing students vary by country, indicating that strategies tailored to local conditions are more necessary than global strategies. As a result, research on students' job preferences has revealed that results vary by region, industrial sector, and other factors affecting their personal situations.

Nevertheless, those studies on students' job preferences did not examine the effect of a specific job task category on job satisfaction at a mining site. A mining job entails several tasks, including mine planning, drilling, blasting, and engineering. These tasks entail a variety of risks for employees. For instance, in comparison to mine planning, drilling and blasting activities increase the risk of fatal accidents in a mining site. Additionally, drilling and blasting are physically demanding tasks that require on-site labor. Given these conditions, drilling and blasting workers are supposed to earn more than mine planning workers. Briefly, mining companies must adjust salaries or compensations based on the different risks and situations of each work task.

The following estimation methods and attributes were used in this study based on previous research.

\section{Materials and Methods}

This study adopted a conditional logit model. When subject $\mathrm{n}$ selects profile $\mathrm{i}$, the subject's utility is provided by $U_{n, i}=V_{n, i}+\varepsilon_{n, i}=X_{n, i} \beta+\varepsilon_{n, i}$, where $V_{n, i}$ is the observable component of $U_{n, i}, \varepsilon_{n, i}$ is the unobservable component of $U_{n, i}, X_{n i}$ are attribute vectors, and $\beta$ is parameters corresponding to each attribute vector. The set of profiles that a subject $\mathrm{n}$ can select is based on $C=\{1,2, \ldots, j\}$. The probability that a subject $\mathrm{n}$ chooses profile $i \in C$ is $P_{n, i}$. When subject n selects profile $\mathrm{i}, U_{n, i}>U_{n, j}(i \neq j)$ must be satisfied. Thus, the following equation is obtained:

$$
P_{n, i}=\operatorname{Pr}\left[U_{n, i}>U_{n, j}, \forall j \in C, j \neq i\right]=\operatorname{Pr}\left[V_{n, i}-V_{n, j}>\varepsilon_{n, j}-\varepsilon_{n, i}, \forall j \in C, j \neq i\right]
$$


Following McFadden [21], $\varepsilon_{n, i}$ and $\varepsilon_{n, j}$ are assumed to be independent with a univariate type I extreme value distribution. Then, the probability that a subject $\mathrm{n}$ chooses profile $i$ is

$$
P_{n, i}=\frac{e^{\mu V_{n, i}}}{\sum_{j \in C} e^{\mu V_{n, i}}}
$$

where $\mu$ is a scale parameter. In this study, $\mu$ is normalized to 1 . This model is known as a conditional logit model. Hence, the log-likelihood function is obtained:

$$
\ln L=\sum_{n=0}^{N} \sum_{i \in C} \delta_{n}^{i} \ln P_{n, i}
$$

where $L$ is likelihood function, $N$ is the number of subjects, and $\delta_{n}^{i}$ is the dummy variable, such that $\delta_{n}^{i}=1$ if subject $\mathrm{n}$ selects profile $\mathrm{i}$ and 0 otherwise. By maximizing the loglikelihood function, the parameters $\beta$ can be estimated.

Marginal willingness to accept is estimated to show the level of monetary values of each attribute. The MWTA is obtained:

$$
M W T A=-\frac{a_{k}}{\beta_{w}}
$$

where $a_{k}$ is a parameter of attribute $k$ and $\beta_{w}$ is a parameter of wage.

The MWTA for each attribute can be determined using the conditional logit model's estimation results. However, conditional logit estimation cannot account for the effects of additional individual characteristics and job selection attributes. As a result, this study also utilized a binomial logit model. The binomial logit model can be used to examine both continuous and categorical variables. When subject $\mathrm{n}$ chooses profile $i$, it implies that $U_{n, 1}>U_{n, 0}$, where $U_{n, 1}$ and $U_{n, 0}$ are the utilities that $\mathrm{n}$ associates with profile $\mathrm{A}$ and profile $\mathrm{B}$, respectively. In utility $U_{n, i}$, the alternative $i$ (1: profile $\mathrm{A} ; 0$ : profile $\mathrm{B}$ ) indicates that individual $\mathrm{n}$ is composed of two parts: a systematic term $\bar{U}_{n, i}$, which depends on attributes vector $\mathrm{X}$ (wage, fatality rate, etc.), and a random term $\varepsilon_{n, i}$ :

$$
U_{n, i}=\bar{U}_{n, i}+\varepsilon_{n, i}
$$

The utility $U_{n, i}$ is not observable. Decision $Y_{n}$ is observed and is valued at 1 if individual $\mathrm{n}$ selects profile $\mathrm{A}$ as a preferred labor condition and 0 if the individual selects profile $B$ as a preferred labor condition. Assuming an individual selects the alternative that presents the greatest utility, the result would be obtained as:

$$
\begin{aligned}
& \operatorname{Pr}\left[Y_{n}=1\right]=\operatorname{Pr}\left[U_{n, 1}>U_{n, 0}\right] \\
& \operatorname{Pr}\left[Y_{n}=0\right]=\operatorname{Pr}\left[U_{n, 0}>U_{n, 1}\right]
\end{aligned}
$$

McFadden (1974) demonstrated that in this case, the probability that subject $\mathrm{n}$ selects alternative 1 is

$$
\operatorname{Pr}\left[Y_{n}=1\right]=\frac{e^{\bar{U}_{n, 1}}}{1+e^{\bar{u}_{n, 1}}}
$$

assuming the random term follows a logistic distribution.

\section{Data Collection}

Data were gathered through a paper-based questionnaire survey in September 2019. This survey adopted a choice-based conjoint (CBC) experiment to clarify the types of labor conditions at a mining site preferred by students who were enrolled in courses related to mining engineering at the National University of Engineering and Pontifical Catholic University of Peru in Peru. The survey process and content were reviewed and approved by both universities. This survey excluded questions on personally identifiable information but included students' ID numbers. The investigation was carried out in each university's 
mining engineering classes. Classes enrolled a total of 356 students. Of these, 214 were from National University of Engineering and 142 from Pontifical Catholic University of Peru. The response rate was $44.6 \%$. A total of 222 students participated in the survey, including males and females aged 19-44 years. The distribution of respondents is shown in Table 1. The questionnaire consisted of a CBC experiment of labor conditions at a mining site and items on individual characteristics, such as university, sex, age, and family, and also risk preferences. The following section elaborates on the choice experiment.

Table 1. Subject details.

\begin{tabular}{ccccc}
\hline Sniversity & Sex & Male Students & Female Students & Total \\
\hline National & 135 & 10 & 145 \\
\hline Private & 64 & 13 & 77 \\
\hline Total & 199 & 23 & 222 \\
\hline
\end{tabular}

This survey was based on an experimental CBC model. In comparison with traditional conjoint analysis, the CBC analysis evaluates preferences naturalistically by observing choice decisions $[22,23]$. Compared with the revealed preference approach, which deals with data obtained from observing peoples' behaviors, the stated preference approach, as CBC model classifies, deals with data obtained from people's hypothetical behaviors, specifically their choice behaviors in hypothetical situations [24]. In the case of work choice behaviors in the mining industry, it is based on the position because of the required skills or work experience rather than on their preferences on labor conditions; therefore the revealed preference approach is not suitable for analyzing the respondents' preference from existing data. Hence, CBC model can elicit the underlying preference of respondents by observing their choices among hypothetical options.

To assess the preferences of students at two universities regarding labor conditions on a mining site, five different questionnaire patterns were formed, each with eight choice sets. Each option set included two hypothetical scenarios involving labor conditions on a mining site. Table 2 shows the options consisting of seven variables. The wage attribute was set to estimate the MWTA value of each variable and to reveal the effect of wage on job selection, which was previously reported as a factor affecting job selection [12]. According to a study, differences in the working environment and injury rates are related to the worker's position and method [25]. Additionally, the fatality rate attribute was included because it is a problematic aspect of the mine work environment. Another study found that the working style attribute influences new employee job selection, and another found that the working style is related to workers' mental health and well-being [26]. Geographical location is included in the attributes, as it is known that it has major effects on workers' health [27]. Owing to Peru's geographical features, some mining sites are at a high altitude, which can affect workers' health. Furthermore, the conflict between local residents and mining companies has been a problem in Peru. A study showed that corporate social responsibility (CSR) activities by the mining company lead to building social capital and good communication between local residents and the mining company [28]. The variables and their definitions are displayed in Table A1 in Appendix A. The questionnaire items include students' sociodemographic characteristics such as sex, age, university, and internship experience at mining site to find preferences among students with common sociodemographic characteristics. 
Table 2. Attributes and levels in the conditional logit model.

\begin{tabular}{cc}
\hline Attribute & Levels \\
\hline Wage (Peruvian sol) & $(30,000,40,000,50,000,60,000)$ \\
\hline Fatality rate (per 100,000 employees) & $(8,16,24)$ \\
\hline Working position & (Mine planning, Blasting, Driller, Geotechnical engineer) \\
\hline Style & (Living near the site, Fly-in/fly-out or Drive-in/drive-out) \\
\hline Method & (Underground mining, Surface mining) \\
\hline Geographical status & (Highland, Coast) \\
\hline CSR activities & (No, Environment, Society)
\end{tabular}

Each option had four common features, specifically job tenure, fixed working hours of $10 \mathrm{~h}$ per day from 7 am to 5 pm, typical insurance cover, and residing in Peru. A combination of the options in a choice set was randomly assigned for each pattern of the questionnaire. Respondents were asked to select their most preferred option from a choice set of two hypothetical options. The questionnaire did not include the option of N/A, not applicable or not available, because the majority of mining students had obtained employment in mining companies as a result of the preliminary interview. The questionnaire was in Spanish, and the following examples are original sentences before they were translated into Spanish.

Specifically, the following question was posed: "Now we will ask your preferences for hypothetical labor conditions in the mining site with different conditions. You will choose one out of four hypothetical job opportunities from A to B. Common features of the proposed job opportunities are (1) tenure jobs, (2) $10 \mathrm{~h}$ per day from 7 am to 5 pm including 1-h break, (3) covering typical insurance such as life insurance, income protection, trauma insurance, and total permanent disability insurance, (4) any hypothetical mining site in Peru. Job opportunities are characterized by eight variables such as average annual wage after three years (Peru sol "S/"), the fatality rate in the mining site per 100,000, work position, working style, mining method, geographic location, and CSR activities. Information: Highland refers to any area at an altitude higher than $3500 \mathrm{~m}$. Coast refers to any area at an altitude lower than $3500 \mathrm{~m}$. In the CSR section, Environment refers to any CSR activity related to the environment such as nature, animals, or planting trees. Society refers to any CSR activity related to people, such as job creation, infrastructure investments, or meeting with locals." Table 3 presents an example of a choice set used for the survey.

Table 3. Example of a choice set in the survey.

\begin{tabular}{cccc}
\hline Question 1 & Working Conditions & A & B \\
\hline $\begin{array}{c}\text { Please choose the most } \\
\text { preferable job from A or B }\end{array}$ & Annual wage including bonus (S/.) & 30,000 & 40,000 \\
\hline Write your answer below & $\begin{array}{c}\text { Fatality rate per 100,000 employees } \\
\text { within a year }\end{array}$ & $8 / 100,000$ & $16 / 100,000$ \\
\cline { 2 - 4 } & Working position & Geotech Engineer & Mine planning \\
\cline { 2 - 4 } & Commuting & Living near the site & Surface \\
\cline { 2 - 4 } & Geographical status & Coast & Coast \\
\hline
\end{tabular}




\section{Results}

The results were computed by the Stata/IC 14.0 software for Windows. The conditional logit model and logit model were adopted in this study. Table 4 summarizes the conditional logit model's results estimated with Equation (3), while Table 5 summarizes the conditional logit model's marginal effect. The statistical significance [29] of the results is described with the asterisks ${ }^{*}, *$, and ${ }^{* * *}$ in the tables which indicate that the coefficients are significantly different from zero at the $10 \%, 5 \%$, and $1 \%$ levels, respectively. According to Table 4, nine variables are statistically significant for determining preferable labor conditions from the perspective of students, including wage, fatality rate, working position dummies such as blasting and geotech engineering, style dummies such as living near the site, CSR activity dummies such as society and environment, method dummies such as underground, and position dummy such as driller. Each coefficient is estimated by referring to a set level as follows: mine planning for the working position, commuting for the style of working, surface mining for method, coast for the geographic location, and no activities for CSR activities. Table 5 shows how the independent variables change while covariates are assumed to be constant. The students' order of preference of variables, referring to the levels, can be observed from the results of the marginal effect of the conditional logit model. Among the variables of working position, mine planning is most preferred by students, followed by blasting and drilling. Living near the site is more preferred than commuting as a working style.

Table 6 shows the MWTA's estimation results, estimated by Equation (4), using the results of the conditional logit model. The monetary value of the attributes can be estimated using the equation of MWTA. The result of MWTA can be interpreted as a monetary value that students expect to receive if the level of the attribute of the working condition changes from referencing level to each other level. MWTA is calculated using the conditional logit model's estimation results, more precisely by dividing the coefficient of each independent variable by the coefficient of the wage (Table 4). According to the results in Table 6, the driller has the highest value for respondents among all job levels. Additionally, the estimation results show that respondents place a higher value on society as a CSR activity.

Table 4. Estimation results of the conditional logit model.

\begin{tabular}{rrrr}
\hline Attribute & Coef. & Std. Err. \\
\hline Wage & & $2.99 \times 10^{-5 * * *}$ & $3.12 \times 10^{-6}$ \\
\hline Fatality & & $-0.052^{* * *}$ & 0.005 \\
\cline { 2 - 3 } Position (referencing mine planning) & $-0.401^{* * *}$ & 0.097 \\
\cline { 2 - 4 } & Blasting & $-0.664^{* * *}$ & 0.097 \\
\cline { 2 - 4 } & Geotech & $-0.184^{*}$ & 0.101 \\
\hline Style (referencing commuting) & Driller & $-0.387^{* * *}$ & 0.069 \\
\hline Method (referencing surface) & Living near site & 0.069 \\
\hline Geographic (referencing coast) & Underground & $-0.155^{* *}$ & 0.069 \\
\hline \multirow{2}{*}{ CSR (referencing no activities) } & High land & $-0.045^{* * *}$ & 0.097 \\
\cline { 2 - 4 } & Society & $0.563^{* * *}$ & 0.083 \\
\hline
\end{tabular}

There were a total of 3552 observations (222 respondents $\times 8$ times questions $\times 2$ options). $\chi^{2}(10)$ is 329.70 . Prob $>$ chi2 $=0.0000$. The asterisks $* * *$, and $* * *$ indicate that the coefficients are significantly different from zero at the $10 \%, 5 \%$, and $1 \%$ levels, respectively. Log-likelihood $=-1935.8606$. 
Table 5. Estimation results of the marginal effect of the conditional logit model.

\begin{tabular}{rrrr}
\hline \multicolumn{1}{c}{ Attribute } & dy/dx & Std. Err. \\
\hline Wage & & $6.68 \times 10^{-6 * * *}$ & $5.51 \times 10^{-7}$ \\
\hline Fatality & & $-0.017^{* * *}$ & 0.001 \\
\cline { 2 - 4 } Position (referencing mine planning) & Blasting & $-0.088^{* * *}$ & 0.022 \\
\cline { 2 - 4 } & Geotech & $-0.148^{* * *}$ & 0.023 \\
\hline Style (referencing commuting) & Driller & $-0.039^{*}$ & 0.022 \\
\hline Method (referencing surface) & Living near site & 0.016 \\
\hline Geographic (referencing coast) & Underground & $0.087^{* * *}$ & 0.016 \\
\hline \multirow{2}{*}{ CSR (referencing no activities) } & High land & $-0.035^{* *}$ & 0.015 \\
\cline { 2 - 4 } & Society & -0.01 & 0.021 \\
\hline
\end{tabular}

There were a total of 3552 total observations (222 respondents $\times 8$ times questions $\times 2$ options). The asterisks $*, * *$ and ${ }^{* * *}$ indicate that the coefficients are significantly different from zero at the $10 \%, 5 \%$, and $1 \%$ levels, respectively.

Table 6. Estimation results of the marginal willingness to accept.

\begin{tabular}{ccc}
\hline & Attribute & MWTA (PEN) \\
\hline & Fatality rate & 1750 \\
\cline { 2 - 3 } Position (referencing mine planning) & Blasting & 13,411 \\
\cline { 2 - 3 } & Geotech & 22,201 \\
\hline Style (referencing commuting) & Driller & 6154 \\
\hline Method (referencing surface) & Living near site & 12,947 \\
\hline Geographical (referencing coast) & Underground & 5198 \\
\hline \multirow{2}{*}{ CSR (referencing no activities) } & High land & 1521 \\
\cline { 2 - 3 } & Society & $-18,818$ \\
\hline
\end{tabular}

Additionally, the MWTA results indicate that respondents prefer to work in a flyin/fly-out style rather than live near a mining site, as previously reported [30]. According to a previous study [12], students appear concerned about the cost of living and the availability of housing in a mining town.

The logit model's results estimated by Equation (8) for the main effects and their interactions with the variables of individual characteristics are summarized in Table 7 . The interaction terms were applied to identify how the effect on the students' job selections of a change in an independent variable depends on the value of another independent variable. The interactions were calculated with the binomial logit model described in the materials and methods section by using the sociodemographic data of students as independent variables in the model. The estimation results of the main effects reveal that wage, fatality rate, blasting, geotech engineer, living near the site, society, and environment are all significant in determining labor conditions. Additionally, the variable "underground" has statistical significance. Meanwhile, the driller and high land variables have a limited effect on labor condition decision making. The logit model without interaction dummies shows the same trend as the conditional logit model, which ensures the independence of the independent variables' signs. 
Table 7. Estimation results of logit model including interactions.

\begin{tabular}{|c|c|c|c|}
\hline \multicolumn{2}{|l|}{ Attribute } & Coef. & Std. Err. \\
\hline \multicolumn{2}{|l|}{ Wage } & $3.24 \times 10^{-5 * * *}$ & $3.25 \times 10^{-6}$ \\
\hline \multicolumn{2}{|l|}{ Fatality } & $0.115^{* * *}$ & 0.042 \\
\hline \multirow{3}{*}{ Position (referencing mine planning) } & Blasting & $-0.69^{* * *}$ & 0.194 \\
\hline & Geotech & $-0.93^{* * *}$ & 0.196 \\
\hline & Driller & -0.289 & 0.202 \\
\hline Style (referencing commuting) & Living near site & $-0.42 * * *$ & 0.071 \\
\hline Method (referencing surface) & Underground & $1.3^{* *}$ & 0.551 \\
\hline Geographical (referencing coast) & High land & -0.05 & 0.071 \\
\hline \multirow{2}{*}{ CSR (referencing no activities) } & Society & $0.605^{* * *}$ & 0.101 \\
\hline & Environment & $0.57 * * *$ & 0.086 \\
\hline Sex (referencing male) & Female & $0.965 * * *$ & 0.288 \\
\hline \multicolumn{2}{|l|}{ Age } & $0.144^{* * *}$ & 0.034 \\
\hline University (referencing private) & National & $-0.319^{* *}$ & 0.162 \\
\hline Internship experience (referencing none) & Yes & $0.343 *$ & 0.202 \\
\hline \multicolumn{4}{|c|}{ Interactions } \\
\hline Fatality $\times$ Sex (referencing male) & Female & $-0.069 * * *$ & 0.019 \\
\hline \multicolumn{2}{|c|}{ Fatality $\times$ Age } & $-0.008^{* * *}$ & 0.002 \\
\hline Method $\times$ Age (referencing surface) & Underground & $-0.069^{* * *}$ & 0.026 \\
\hline \multirow{3}{*}{$\begin{array}{l}\text { Position (referencing mine planning) } \times \\
\text { University (referencing private) }\end{array}$} & Blasting $\times$ National & $0.486^{* *}$ & 0.22 \\
\hline & Geotech $\times$ National & $0.459 * *$ & 0.222 \\
\hline & Driller $\times$ National & 0.289 & 0.23 \\
\hline \multirow{3}{*}{$\begin{array}{l}\text { Position (referencing mine planning) } \times \\
\text { Internship experience (referencing none) }\end{array}$} & Blasting $\times$ Yes & -0.342 & 0.272 \\
\hline & Geotech $\times$ Yes & $-0.475 *$ & 0.275 \\
\hline & Driller $\times$ Yes & $-0.542 *$ & 0.285 \\
\hline
\end{tabular}

There were a total of 3552 observations (222 respondents $\times 8$ times questions $\times 2$ options). $\chi^{2}$ (10) is 404.24. Prob $>$ chi2 $=0.0000$. The asterisks ${ }^{* * *}$, and ${ }^{* * *}$ indicate that the coefficients are significantly different from zero at the $10 \%, 5 \%$, and $1 \%$ levels, respectively. Log-likelihood $=-2259.9364$.

Additionally, the estimation results show that job selection is influenced by the interaction terms between the main factors and respondents' individual characteristics. The interaction between fatality rate and sex shows that female respondents prefer safer labor conditions than male students, as previously reported. As a result, the differences in safety conditions between underground and surface mining, as well as gender differences in risk aversion, had a significant effect on job selection trends.

The interaction between fatality rate and age indicates that, when compared to younger respondents, older respondents prefer fatal accident work environments less. The negative sign of the coefficient of interaction between mining method and age indicates that older respondents, in comparison to younger respondents, do not prefer to work at an underground mining site. In terms of employment positions, there are significant interactions between blasting and national, geotech and national, geotech and internship experience, and driller and internship experience. Positive signs indicate that, when compared to private university students, national university students prefer blasting and geotechnical engineering to mine planning for labor conditions. The results of the interactions between positions and internship experience indicate that respondents with internship experience do not prefer geotech engineering and driller positions to mine planning for labor conditions. 


\section{Discussion}

Predictably, the study's findings indicate that students prefer jobs with higher wages and lower fatality rates. In terms of labor conditions, students preferred mine planning, followed by driller, blasting, and geotech engineering. A previous study conducted on Australian students [11] showed that mine planning, which does not require heavy labor work, was the most preferred. The result of MWTA implies that other positions have a lower value and should yield better compensation than mine planning. These results imply that mining companies must consider the labor conditions of drilling, blasting, and geotech engineering. Additionally, the conditional logit model results indicate that students do not prefer to live near the site, despite the negative effects on their mental health, lifestyle, and family associated with commuting [26,31-33], probably because of Peruvian geographic characteristics. Nevertheless, geographical location in the conditional logit model had a limited effect on the students' working condition preferences and they appeared to like to spend their private time in the city. This result indicates that the students might have underestimated the psychological and physical risks associated with labor conditions. The impact of occupational health in the mining sector on the turnover rate was examined [34]. Regarding Peru's geographical features, a study discovered that mining workers were harmed by the high altitude. To close the gap between their perceptions and reality on the ground, an objective and in-depth understanding of the facts is required, as is health support. Specifically, a university-level course on occupational health appears to be effective. Moreover, the conditional logit and logit models indicate that CSR activities benefiting society and the environment have a positive effect on university students' job selection decisions. This finding demonstrates that a mining company's promotion of CSR activities can result in a stronger relationship with local residents [28] and has a positive effect on employing students. As a note, depending on the conditions among local residents, the mining company, and other stakeholders, CSR activities have a limited effect on the construction of the relationship [28].

The study's findings indicate that sociodemographic characteristics and factors have an effect on job selection in the mining industry. To be more precise, the interaction between individual characteristics and the major variables demonstrates a significant correlation with job selection. An earlier study in Australia showed differences in students' preferences for job selection by sex and students' university [11]. Similar trends were also assessed in the case of Peru. The interaction between fatality rate and sex is associated with differences in risk aversion by sex [35]. The interaction between position and university can be explained by the difference in course materials. The National University of Engineering is primarily composed of faculty that are related to engineering; by contrast, the Pontifical Catholic University of Peru is composed of several faculties related to social science. Students who experienced internships at a mining site did not prefer to work for geotech engineering and blasting but preferred mine planning compared with students without internship experience at a mining site. The results suggest that the internship experience might influence students' job selection and lower the preferences of working positions requiring heavy labor.

\section{Conclusions}

The purpose of this study was to identify the factors affecting Peruvian mining students' preferences for labor conditions in a mining site using CBC analysis. A paper-based questionnaire survey on students enrolled in mining courses at the National University of Engineering and the Pontifical Catholic University of Peru was carried out to collect data. The questionnaire included questions about students' sociodemographic characteristics, with the assumption that there is a correlation between sociodemographic characteristics and labor conditions.

The analysis's findings indicate that labor conditions at mining sites can be optimized by adapting them to specific individual characteristics of potential mining workers, potentially resulting in more efficient labor conditions for companies and workers. Additionally, 
the MWTA estimation results indicate the potential values assumed to each fact of labor conditions by respondents.

Finally, this study has limitations. This study does not represent the collective preferences of all mining students in Peru regarding labor conditions. Despite the statistical significance found in this study, the findings are not generalizable to all Peruvian mining students due to the small sample size and differences in preferences across sociodemographic characteristics. Although this study examined the students' preferences on labor conditions in mining sites, it does not imply that meeting those preferences surely or directly imparts students an increased or satisfying well-being in their work.

As a result, future studies are encouraged to include a larger sample size in order to generalize the findings. Additionally, including a comprehensive sociodemographic variable would allow for a more in-depth understanding of the study's findings. Furthermore, in order to apply the study's findings to broader trends in mining worker preferences, an in-depth examination of the preferences of experienced mining workers could enable the effective employment of potential workers with extensive backgrounds.

Author Contributions: Conceptualization, S.M.; supervision, Y.I.; investigation, H.G.O.G. All authors have read and agreed to the published version of the manuscript.

Funding: This research was funded by JSPS KAKENHI grant number JP18H03433.

Institutional Review Board Statement: Ethical review and approval were waived for this study, due to the characteristics of the survey the institution considered it not applicable.

Informed Consent Statement: Informed consent was obtained from all subjects involved in the study.

Data Availability Statement: The data presented in this study are available on request from the corresponding author. The data are not publicly available due to their containing information that could compromise the privacy of research participants.

Acknowledgments: We thank José Corimanya from Universidad Nacional de Ingeniería and Maribel Guzman from Pontificia Universidad Católica del Perú for supporting and advising for our survey in the universities.

Conflicts of Interest: The authors declare no conflict of interest.

Appendix A

Table A1. Variables and definitions.

\begin{tabular}{cc}
\hline Variables & Definitions \\
\hline Wage & A numerical variable of an average annual wage after three years (S/.) \\
Fatality rate & A numerical variable of fatality rate at the mining site per 100,000 employees \\
Mine planning & A dummy variable of working position at a mining site \\
Blasting & A dummy variable of working position at a mining site \\
Drilling & A dummy variable of working position at a mining site \\
Aeotechnical engineer & A dummy variable of working position at a mining site \\
Living near site & A dummy variable of working style assuming living near the mining site \\
Fly-in fly-out & A dummy variable of working style assuming commuting by air to the mining site \\
Underground mining & A dummy variable of mining method that excavates valuable materials by drilling underground \\
Surface mining & A dummy variable of mining method that excavates valuable materials near the surface of the earth \\
Coast & A dummy variable of altitude of a mining site that is lower than $3500 \mathrm{~m}$ \\
High land & A dummy variable of altitude of a mining site that is higher than $3500 \mathrm{~m}$ \\
No (CSR) activities & A dummy variable of CSR activities assuming no CSR activities conducted by mining company \\
Society & A dummy variable of CSR activities assuming CSR activities for society conducted by mining company \\
Environment & A dummy variable of CSR activities assuming CSR activities for environment conducted by mining \\
& company \\
\hline
\end{tabular}




\section{References}

1. Loayza, N.; Rigolini, J. The Local Impact of Mining on Poverty and Inequality: Evidence from the Commodity Boom in Peru. World Dev. 2016, 84, 219-234. [CrossRef]

2. Asner, G.P.; Llactayo, W.; Tupayachi, R.; Luna, E.R. Elevated rates of gold mining in the Amazon revealed through high-resolution monitoring. Proc. Natl. Acad. Sci. USA 2013, 110, 18454-18459. [CrossRef]

3. U.S. Geological Survey. Mineral Commodity Summaries; U.S. Geological Survey: Reston, VA, USA, 2020; p. 200. [CrossRef]

4. Delgado, A.; Romero, I. Environmental conflict analysis using an integrated grey clustering and entropy-weight method: A case study of a mining project in Peru. Environ. Model. Softw. 2016, 77, 108-121. [CrossRef]

5. Gonzalez, D.J.X.; Arain, A.; Fernandez, L.E. Mercury exposure, risk factors, and perceptions among women of childbearing age in an artisanal gold mining region of the Peruvian Amazon. Environ. Res. 2019, 179, 108786. [CrossRef]

6. Kemp, D.; Bond, C.J.; Franks, D.M.; Cote, C. Mining, water and human rights: Making the connection. J. Clean Prod. 2010, 18, 1553-1562. [CrossRef]

7. Defensoría del Pueblo. Reporte de Conflictos Sociales N. ${ }^{\circ} 190$; Defensoría del Pueblo: Lima, Peru, 2019.

8. Kemp, R.; Pearson, P. Final Report MEI Project about Measuring Eco-Innovation; UNU-MERIT: Maastricht, The Netherlands, 2007.

9. Aron, A.S.; Molina, O. Green innovation in natural resource industries: The case of local suppliers in the Peruvian mining industry. Extr. Ind. Soc. 2019, 7, 1-13. [CrossRef]

10. Fundación Chile. Fuerza Laboral Minería del Perú 2018; Fundación Chile: Santiago, Chile, 2018; p. 80.

11. Ito, Y.; Mikami, S.; Jang, H.; Taheri, A.; Tanaka, K.; Kawamura, Y. University Students' Preferences for Labour Conditions at a Mining Site: Evidence from Two Australian Universities. Resources 2020, 9, 29. [CrossRef]

12. Windle, J.; Rolfe, J. Using discrete choice experiments to assess the preferences of new mining workforce to commute or relocate to the Surat Basin in Australia. Resour. Policy 2013, 38, 169-180. [CrossRef]

13. Amponsah-Tawiah, K.; Jain, A.; Leka, S.; Hollis, D.; Cox, T. Examining psychosocial and physical hazards in the Ghanaian mining industry and their implications for employees' safety experience. J. Saf. Res. 2013, 45, 75-84. [CrossRef]

14. Street, T.D.; Lacey, S.J.; Somoray, K. Employee stress, reduced productivity, and interest in a workplace health program: A case study from the Australian mining industry. Int. J. Environ. Res. Public Health 2019, 16, 94. [CrossRef] [PubMed]

15. Varga, J.; Nagy, I.; Szirtes, L.; Pórszász, J. Physiological strain in the Hungarian mining industry: The impact of physical and psychological factors. Int. J. Occup. Med. Environ. Health 2016, 29, 597-611. [CrossRef] [PubMed]

16. Di Marco, D.; Arenas, A.; Giorgi, G.; Arcangeli, G.; Mucci, N. Be friendly, stay well: The effects of job resources on well-being in a discriminatory work environment. Front. Psychol. 2018, 9, 1-8. [CrossRef] [PubMed]

17. Omar, M.K.; Zakaria, A.; Ismail, S.; Sin, J.S.L.; Selvakumar, V. Job Selection Preferences of Accounting Students in Malaysian Private Universities. Procedia Econ. Financ. 2015, 31, 91-100. [CrossRef]

18. Meyerding, S.G.H. Job preferences of agricultural students in Germany-A choice-based conjoint analysis for both genders. Int. Food Agribus Manag. Rev. 2018, 21, 219-236. [CrossRef]

19. Blaauw, D.; Erasmus, E.; Pagaiya, N.; Tangcharoensathein, V.; Mullei, K.; Mudhune, S.; Goodman, C.; English, M.; Lagarde, M. Policy interventions that attract nurses to rural areas: A multicountry discrete choice experiment. Bull. World Health Organ. 2010, 88, 350-356. [CrossRef] [PubMed]

20. Cleland, J.A.; Johnston, P.W.; Anthony, M.; Khan, N.; Scott, N.W. A survey of factors influencing career preference in new-entrant and exiting medical students from four UK medical schools. BMC Med. Educ. 2014, 14, 1-10. [CrossRef]

21. McFadden, D. Conditional Logit Analysis of Qualitative Choice Behavior; Academic Press: New York, NY, USA, 1974; pp. 105-142. [CrossRef]

22. Green, P.E.; Krieger, A.M.; Wind, Y. Thirty Years of Conjoint Analysis: Reflections and Prospects. Interfaces 2001, 31, 56-73. [CrossRef]

23. Green, P.E.; Srinivasan, V. Conjoint Analysis in Consumer Research: Issues and Outlook. J. Consum. Res. 1978, 5, 103. [CrossRef]

24. Adamowicz, W.; Louviere, J.; Williams, M. Combining Revealed and Stated Preference Methods for Valuing Envrimental Amenities. J. Environ. Econ. Manag. 1994, 26, 271-292. [CrossRef]

25. Government of Western Australia D of M. Safety Performance in the Western Australian Mineral Industry, Accident and Injury Statistics 2016-2017; Department of Mines, Industry Regulation and Safety: Western Australia, Australia, 2018; p. 46.

26. Lifeline, W.A. FIFO/DIDO Mental Health Research Report 2013; Lifeline WA: East Perth, WA, Australia, 2013 ; p. 108.

27. Hnhm, D.; Eamm, D. High Altitude Pulmonary Edema: Epidemiologic Observations in Peru. Chest 1978, 74, 372-376. [CrossRef]

28. Cesar, S.; Jhony, O. Corporate Social Responsibility supports the construction of a strong social capital in the mining context: Evidence from Peru. J. Clean Prod. 2020, 267, 122162. [CrossRef]

29. Greenland, S.; Senn, S.J.; Rothman, K.J.; Carlin, J.B.; Poole, C.; Goodman, S.N.; Altman, D.G. Statistical tests, P values, confidence intervals, and power: A guide to misinterpretations. Eur. J. Epidemiol. 2016, 31, 337-350. [CrossRef]

30. Rolfe, J.; Miles, B.; Lockie, S.; Ivanova, G. Lessons from the Social and Economic Impacts of the Mining Boom in the Bowen Basin 2004-2006. Australas. J. Reg. Stud. 2007, 13, 134-153.

31. Cooke, D.C.; Kendall, G.; Li, J.; Dockery, M. Association between pregnant women's experience of stress and partners' fly-in-flyout work. Women Birth 2018, 1-9. [CrossRef]

32. Rebar, A.L.; Alfrey, K.L.; Gardner, B.; Vandelanotte, C. Health behaviours of Australian fly-in, fly-out workers and partners during on-shift and off-shift days: An ecological momentary assessment study. BMJ Open 2018, 8, e023631. [CrossRef] [PubMed] 
33. Gardner, B.; Alfrey, K.L.; Vandelanotte, C.; Rebar, A.L. Mental health and well-being concerns of fly-in fly-out workers and their partners in Australia: A qualitative study. BMJ Open 2018, 8, e019516. [CrossRef] [PubMed]

34. Amponsah-Tawiah, K.; Ntow, M.A.O.; Mensah, J. Occupational Health and Safety Management and Turnover Intention in the Ghanaian Mining Sector. Saf. Health Work 2016, 7, 12-17. [CrossRef] [PubMed]

35. Croson, R.; Gneezy, U. Gender Differences in Preferences 2009. J. Econ. Lit. 2009, 47, 448-474. [CrossRef] 